\title{
Social Sustainability and Mixed Landuse, Case Study of Neighborhoods in Nagpur, India
}

\author{
Sarika Bahadure and Rajashree Kotharkar
}

\begin{abstract}
Social sustainability focuses on the type of development that promotes social interaction and inclusion. It gives emphasis to inclusive community, social cohesions, quality of life, social equity and diversity.

Segregated landuse has single land use and creates social impacts like social inequalities, exclusion, increased crime rate and physical and psychological problems. Mixed landuse development has multiple compatible land uses like residential, commercial, leisure, etc. within a closed proximity. These diverse uses tend to encourages walking thus enhancing visual and verbal interaction. This paper studies the significance of understanding the notion of mixed land use to achieve social sustainability. Various social parameters like accessibility, diversity, vitality, community cohesion, natural surveillance, safety, quality of life, sense of belonging and (anti)social behaviour has been studied in the context of mixed and segregated landuse areas.
\end{abstract}

Supporting the literature review the study is further extended in six neighbourhoods with varying mix of residential, mix, commercial and other (open area/garden/institutional) land use for the city Nagpur, India. Accessibility, availability and quality of the amenities in the closed proximity and the age of the neighbourhood are the major decisive parameter that affects the social sustainability.

Keywords--- Accessibility, Mixed Landuse, Neighbourhood, Social Sustainability

\section{INTRODUCTION}

$\mathrm{I}$ ndustrial revolution led to a development pattern with economic growth as a priority while degrading the environment. In 1970's, the conflict between environment and development was first acknowledged and the term sustainable development (SD) was coined and defined as "the development which meets the needs of the present generation without compromising the ability of the future generation to meet their own needs" (Brundtland Commission, 1987). The three pillars of sustainability i.e. social, economical and environmental, together contribute to a healthy and productive present and future community. Sustainability is related to creating and maintaining the quality of the life in a

Sarika Bahadure, Assistant Professor and PhD Scholar, Department of Architecture and Planning, Visvesvaraya National Institute of Technology (VNIT), Nagpur,India.E-mail:sarika_wa@yahoo.com

Rajashree Kotharkar, Associate Professor, Department of Architecture and Planning, Visvesvaraya National Institute of Technology (VNIT), Nagpur, India.E-mail:rskotharkar@gmail.com

DOI: 10.9756/BIJIEMS.1744 community. A community cannot exist without people and their interaction. The inhabitants influence development when they choose where to live, work and play. Social aspect has major capacities to enable immediate and positive change for sustainability but then also the social dimension of sustainability has traditionally received less attention than the environment and economic dimensions because of the difficulty in defining and measuring social sustainability (Richmond, 2012).

Mixed landuse development plays a crucial role in enhancing social aspect. Thus, this paper focuses on the aspect of social sustainability its significance to understand the notion of mixed landuse and support the literature study with the case study of six neighbourhoods with varying landuse mix in the urban context of Nagpur, India.

\section{SOCIAL SUSTAINABILITY}

Social sustainability focuses on the type of development that promotes social interaction, social inclusion and cultural enrichment. It gives emphasis to inclusive community, social cohesion, quality of life, social equity and diversity which are integral to the long-term sustainability of communities.

\subsection{Social Sustainability and Spatial Planning}

It's a common practice that economic development and design issues (economic competitiveness, physical infrastructure and public private partnership) are kept at priority in landuse planning. Urban planning and development strategy engross community's physical infrastructure like water supply, sewage disposal, solid waste, roads and electrical utilities. Environmental concerns in last three decades showed significant implications for the design and operation of the physical infrastructure such as conservation and ecological management of storm water and sewage; resource conservation; walk and transit supportive environments, etc. A community is composed of people and places where they live. Thus, community must not only be environmentally sustainable, but also be socially sustainable. Physical design directly cannot ensure that individuals, families and communities will lead sustainable lifestyles, but the inclusive design supporting social aspects (school, health centers, parks, community centers, etc) can help the communities to be socially sustainable (Hancock).

The rise in the quantitative research approach for planning the urban areas can be effortlessly worked out for the economic aspects. But social aspects such as health wellbeing, safety, sense of place, equity, etc are difficult to put on the measurement scales. The measurement of social sustainability currently uses simple demographic indicators as population 
growth, gender ratio, income and health statistics. Thus, the notion of social sustainability is grey and ill-defined in the aspect of planning.

Urban designer Jan Gehl focuses on the creation of pedestrian friendly urban environments to promote street activities. The outdoor activities are a) necessary (work or shop); b) optional (exercise or play); and c) social activities. Resident's preference to undertake optional activities are related to the design of the outdoor environment and other factors like weather. An outcome of this, social activities happen like people sit, talk and interact with each other. The outdoor environment thus escalates the amount of activity (Gehl, 1971). These social activities are vital to a vibrant community as they provide the opportunity for everyone to have social contact, either passive, through watching and listening to passerby, or active, through meeting and engaging with friends. This environment generates the strong sense of place and community (Kavanagh, 2010).

According to Liam Kavanagh, there are six physical factors effecting social sustainability: i) Townscape Design configuration of built forms and interstitial space; ii) Provision of Social Infrastructure- proximity and number of schools, medical facilities, meeting areas, and recreational facilities; iii) Availability of Job Opportunities; iv) Accessibility to all; v) Ability to fulfil psychological needs; and vi) Preservation of local characteristics- conservation (Kavanagh, 2010). Landcom, Sydney has a Social Sustainability Policy based on the social determinants of health and their application in landuse. It aims at providing opportunities for mixed communities (ethnicity, gender and age) with diversity in housing and landuse (Petersen, 2009).

\section{MIXED LANDUSE}

The physical environment enhancing social sustainability can be created by mixed landuse development. Mixed landuse is an appropriate mix of various land uses in an area, where a variety of living activities like live, work, shop and leisure are in close proximity. As mixed use areas tend to promote walk ability and social inclusion, they are safe and accessible thus, persuade social aspect.

\subsection{Historical Perception}

i. Traditional Neighborhood and Mixed Landuse: Human being wishes to fulfil his basic needs within short distances. He wishes and prefers to have varying activities within his reach. In traditional settlements multiple uses were provided in the same vicinity. These settlements were self-contained, walk able and compact and had mixed land uses. There was a strong relationship between the workplace, living space, recreation and other ancillary activities. Group dynamics subsisted and can be proved by the presence of great bath, granary stores and religious buildings which involved group activities (R.S. Kotharkar and S.P. Bahadure, 2010).

ii. Industrial Landuse and Segregated landuse: After Industrial revolution, existing towns expanded and new towns like industrial and satellite towns were created with strict land use zoning separating the uses.
Low density, segregated sprawl development was favored to separate the dwelling and workplace resulting to social exclusion and economic inequity especially for the urban poor. Landuse was generated by economic separation of the producer and consumers. Towns like Le Visient built in 1858 had complete segregation of residence, schools, shops, factories and railways stations (R.S. Kotharkar and S.P. Bahadure, 2010).

iii. Post world war, urban planning policies continued segregated landuse zoning. CIAM (Congre's Internationaux d'Architecture Moderne) advocated the 'Functional City' in which the four main land uses of the city (housing, employment, recreation and transport) were clearly separated. To enforce such land use segregation, planners invented powerful regulatory mechanism and the zoning code (L. Eric and B. Frank, 2006). Mass exodus from central city increased the physical distance and thus, dependency on automobile increased resulting in increased pollution and resource depletion. The movement of segregated landuse reached its zenith in 1960s.

iv. Mixed use revival: In the last three decades sustainable development globally led to the various approaches like new urbanism, urban revitalization, regenerating brownfields, transit oriented development, smart growth and eco-city renewed the interest in mixed-use development. This concept started enhancing the community based society, proximity to the facilities thereby increasing walk ability and interaction, equity and health well being thus promoting social sustainability.

\subsection{Segregated Landuse and Social Un-Sustainability}

Rigid landuse separation is observed where there is a presence of large powerful authority. The political authoritarian governments (the labour town Kahun, ancient Egypt); or economically powerful authority $\left(19^{\text {th }}\right.$ century company town, industrial power) (Procos, 1976); or both politically and economically powerful authority (British in India) had a strong role in segregating the commons from the elites.

Land use separation either due to income or racial severance causes socio-economic impacts. The community with low diversity of housing and business types creates dull and inactive environment. The spatial segregation in United States has resulted in the issues of local revenue and quality of local services like disparity in school quality, health care and transportation. Segregation of uses and restricted access contributes in growing the social inequalities (G. Rosalind, S. Francisco and S. Martim , 2000). The neighborhood with segregation in public spaces and other uses are relatively isolated as compared to the areas with mixed spatial configuration. Spatially segregated neighborhoods are highly dependent on accessibility especially through public transportation, bus stops and playgrounds (Legeby, 2009).

Increase in physical distance due to landuse separation of residences, supermarkets and employment centers create car dependent communities. The commute places are far from 
one another thereby reducing walking or cycling habits and it results in lack of physical exercise and creates health related problems like obesity. Air pollution from roadway traffic has negative effects on human health. The streets and neighborhood open spaces tend to be vacant during non working hours and are prone to anti-social activities. Such areas especially in suburbs are more vulnerable to theft and physical assault especially for single occupants, children and elderly persons.

\subsection{Mixed Landuse, Social Sustainability}

The segregated landuse was not accepted by the people especially in developing countries. So encroachment and informal development happened in single use areas. The tendency of doing work and living together helped in mutually reinforcing and monitoring both.

According to Jane Jacobs, the conventional way of urban planning and policies which had strict zoning laws creates isolated unnatural urban spaces. She mentioned dense, mixeduse neighborhoods are the strong proponents for the safe and socio-economically active growth (Jacobs, 1961). The notion of 'sustainable lifestyle' in America (1980's) was based on using less cars and less resources and making the cities more attractive, viable and safer to live and work. Mixing different land uses in compact setting was seen as a positive contribution in planning policies (Coupland).

Many social benefits are associated with good urban design based on mixed landuse concept.

i. Health: There is a clear relationship between one's health, well being and the nature of built environment. Increased physical activity is enhanced by mixed use in terms of walking and cycling to fulfill basic needs which in turn helps in keeping good health. Association with provision of active street, multipurpose open green space improves mental well being. To promote active community environments, mixed land use, high density and transportation plan play an important role. Land-use policies and implementation tools that support non motorized transportation improvement and mixed land use foster diverse environments conducive to various types of physical activities like greenways, parks, open space, and walkable areas (S.A. Aytur et al, 2007). The performance of the Body Mass Index (BMI) model with six land use categories suggests that the presence of mixed land uses improves walkability (B.Barbara et al, 2009) and thus increases interaction in a neighborhood and maintains physical fitness.

ii. Equity and Diversity: Sustainable urban structure demands mix of diverse housing types based on functions, income and forms. Single family, multifamily, housing for different income groups, low rise, mid rise and high rise apartments can be integrated together in the same layout. It ensures people of various socio-economic classes interact and share symbiotic relationship. Symbiosis between the rich and poor can be achieved by rich providing employment to the poor in the same cluster. iii. Safety and Surveillance: Perceptions of safety depends on the nature and extent to which people use various spaces and places. Street and place design that aims to reduce crime can enhance the physical, mental and social wellbeing of a community. Neighbourhoods with mix of land uses promote high level of activity on the street keeping the streets safe. Children feel safe to play or cycle, elderly can meet and talk and strangers might feel they are intruding. Women feel safe and walk more when basic need destinations generate foot traffic and natural surveillance (L.S. Anastasia and F.Camille, 2009). The fear of being a victim in crime also reduces.

iv. Vitality, Attractiveness and Aesthetics: Mixed use schemes enhance the vitality and attractiveness of town-centre environments, provide housing choice, and promote sustainable modes of transport (DCLG, 2006). Appropriate mix of housing of different tenure, sizes and types creates a lively atmosphere and make the neighbourhood more attractive and creates better quality town centers. A fine-grained mix of attractive destinations, good aesthetic qualities (such as tree cover) in a neighbourhood supports walking for various activities and pleasure (Handy, 1996).

v. Employment: Intensified site utilization is an economic solution for mixed land use development. Business activities and employments are generated in mixed land use development. A building or a complex with twenty-four hour use serves a variety of facilities to occupational or social grouping. Mixed landuse increases economic viability of the development project giving a chance for the developer to plan and consider for affordable housing and lower commercial rents. In the Downtown of city of Los Angeles, mixed-use development is creating more and diverse jobs (retail commercial and professional services, entertainment, health care, etc.) than industrial development (Committee, 2008).

vi. Interaction and Sense of Belonging: The aspect of togetherness and bonding is exhibited by members of a mixed use community. As people perform various activities (live, shop, play and/or work) in the same vicinity has higher frequency to meet, greet, smile \& talk thus connecting the community. This pattern gives a chance for the people of different age groups to interact among themselves and create an inclusive community.

vii. Accessibility: Mixed use neighbourhood has more convenient access to people, places, and activities. This has the social benefit of greater user satisfaction, social connectedness and enhanced viability of ancillary activities.

viii. Quality of Life ( $Q o L)$ : QoL plays an important role in achieving sustainability. Social participation; employment levels; relationships; healthcare; liveability; crime etc. are the indicators for QoL and they can be enhanced by inclusive physical planning and mixing the land uses. Mixed landuse neighbourhood becomes attractive for the residents 
and workers to balance quality of life criteria with salary (E.A.Tombari, 2005).

Even though mixed landuse has many benefits but these areas are also associated with some problems which need to be tackled.

i. Anti-social behavior: Mixed use area generally have low crime rate but in lower income neighborhood unsocial behavior exists. Youth nuisance and antisocial behavior are frequently found in high density, mixed tenure, low income areas due to multiple deprivations like inadequate education, unemployment, poor infrastructure or rental housing. The problem can be sorted out by a) multi-agency partnerships (strategic and operational partnership); b) engagement of residents to build community capacity; c) developing effective interventions; and d) acceptable behavior contracts (ODPM, 2003).

ii. Noise: High \& Medium Density mixed use householders (more likely) see noise as a serious problem (Saville-Smith, 2010). Noise from the certain use type like restaurant and clubs during night time creates problems. This issue could be sorted out by means of proper design and managing noise at source and at receiving end.

\subsection{Mixed Landuse Measures for Social Aspects}

Mixed use can be measured by ratio of jobs to residents at the neighborhood level; or number of various activities/uses within a given distance (typically $1 / 4$ mile) of residences; or number of walking destinations in a neighborhood; or by entropy index; or dissimilarity index. To assess the social aspect in a community, table 1 is prepared to guide in selecting the indicators and their measurement unit. A correlation matrix (table 2) is developed to understand the social aspects affecting the mixed use environment. The manifestation or mitigation action guides the stakeholder to comprehend the behavior pattern (S.P. Bahadure and R.S. Kotharkar, 2010).

Table 1: Indicators Influencing Social Sustainably with Measurement Units

\begin{tabular}{|c|c|}
\hline Factors & Measurement Unit \\
\hline $\begin{array}{l}\text { Provision of } \\
\text { facilities }\end{array}$ & $\begin{array}{l}\text { Ratio of residential to non-residential land; } \\
\text { Quantity and quality of facilities }\end{array}$ \\
\hline $\begin{array}{l}\text { Segregation and } \\
\text { equity }\end{array}$ & $\begin{array}{l}\text { Percentage }(\%) \text { of different } \\
\text { ethnic/income/age/gender group/ households; } \\
\text { Owned/rented, car less, able/vulnerable } \\
\text { households; Average area per household }\end{array}$ \\
\hline Accessibility & $\begin{array}{l}\text { Average distance to nearest store, Green } \\
\text { Spaces; Availability of transit and walk; \% of } \\
\text { car/transit/walk users }\end{array}$ \\
\hline Job accessibility & $\begin{array}{l}\% \text { of employees working within/outside the } \\
\text { neighborhood; } \% \text { of low/ high wages, } \\
\text { skilled/unskilled jobs }\end{array}$ \\
\hline Affordable housing & $\begin{array}{l}\text { Average price of lower cost dwellings } \\
\text { relative to average income of households; } \\
\text { average rent; level of homelessness }\end{array}$ \\
\hline $\begin{array}{l}\text { Safety /Crime } \\
\text { /Surveillance }\end{array}$ & $\begin{array}{l}\text { No of crimes reported; No of people on } \\
\text { streets and other open spaces }\end{array}$ \\
\hline Health Well being & $\begin{array}{l}\% \text { of residents with long-term illness; } \% \text { of } \\
\text { residence with mental/physical illness }\end{array}$ \\
\hline
\end{tabular}

\begin{tabular}{|l|l|}
\hline $\begin{array}{l}\text { Vitality \& } \begin{array}{l}\text { Community } \\
\text { Cohesion }\end{array} \\
\text { Quality of Public } \\
\text { Realm }\end{array}$ & $\begin{array}{l}\text { \% of people interacting on street or public } \\
\text { place of people greet/smile; \% of people familiar } \\
\text { with neighborhood }\end{array}$ \\
\hline Sense of belonging \\
$\begin{array}{l}\text { public spaces; } \text { tho. of people interacting in } \\
\text { these spaces; Active Street frontage }\end{array}$ \\
\hline Cultural Resources & Priendly/non Friendly neighborhood \\
\hline
\end{tabular}

Table 2: Correlation Matrix to Understand the Mixed use Social Aspect and its Manifestation

\begin{tabular}{|c|c|c|}
\hline Key Term & Behavior Pattern & Manifestation/Action \\
\hline Walk ability & $\begin{array}{l}\text { People prefer to } \\
\text { walk/cycle for basic } \\
\text { needs; Visual/ verbal } \\
\text { Interaction }\end{array}$ & $\begin{array}{l}\text { Less use of automobile; } \\
\text { Health issues reduces; } \\
\text { Design Parameters (Street } \\
\text { furniture, sidewalks) }\end{array}$ \\
\hline $\begin{array}{l}\text { Open spaces } \\
\text { with human } \\
\text { scale }\end{array}$ & $\begin{array}{l}\text { Group Dynamics; } \\
\text { Surveillance; Kids } \\
\text { play without fear; } \\
\text { Elderly people relax }\end{array}$ & $\begin{array}{l}\text { Interaction among } \\
\text { different age groups; } \\
\text { Frontage/ Openings/Blank } \\
\text { facade }\end{array}$ \\
\hline $\begin{array}{l}\text { Closeness of } \\
\text { different } \\
\text { land uses }\end{array}$ & $\begin{array}{l}\text { Reduce need for } \\
\text { automobile; Time } \\
\text { Saving; Association } \\
\text { and interaction }\end{array}$ & $\begin{array}{l}\text { Less pollution/ less } \\
\text { carbon footprint; Time for } \\
\text { self and community; } \\
\text { Efficiency; Compatibility } \\
\text { of uses }\end{array}$ \\
\hline $\begin{array}{l}\text { Mix of } \\
\text { tenure and } \\
\text { housing } \\
\text { typology }\end{array}$ & $\begin{array}{l}\text { Diversity; Synergy } \\
\text { increases; Group } \\
\text { dynamics and; } \\
\text { Inclusive community }\end{array}$ & $\begin{array}{l}\text { Affiliation; Instrumental } \\
\text { and Classical Learning }\end{array}$ \\
\hline $\begin{array}{l}\text { Financing } \\
\text { and } \\
\text { feasibility }\end{array}$ & $\begin{array}{l}\text { Networking \& } \\
\text { coordination; } \\
\text { Awareness; Cost } \\
\text { efficiency }\end{array}$ & $\begin{array}{l}\text { Acceptability; Public } \\
\text { subsides; Location (dis- } \\
\text { advantages; Public } \\
\text { revenue ) }\end{array}$ \\
\hline Governance & $\begin{array}{l}\text { Learned behavior; } \\
\text { Social awareness; } \\
\text { Leadership; } \\
\text { Motivation }\end{array}$ & $\begin{array}{l}\text { Mass communication; } \\
\text { Dedication; Publicity \& } \\
\text { propaganda; Tax benefits; } \\
\text { Networking }\end{array}$ \\
\hline $\begin{array}{l}\text { Planning } \\
\text { and Design }\end{array}$ & $\begin{array}{l}\text { Complex (norms, } \\
\text { design); Decision } \\
\text { making; Functional } \\
\text { utility and economical }\end{array}$ & $\begin{array}{l}\text { Dedication; Harmonizing } \\
\text { Conflicting land uses; } \\
\text { Innovation and creativity }\end{array}$ \\
\hline $\begin{array}{l}\text { Life and } \\
\text { quality }\end{array}$ & $\begin{array}{l}\text { Vibrant and active; } \\
\text { Inclusive; Strong } \\
\text { social networking } \\
\end{array}$ & Attention; Affiliation \\
\hline $\begin{array}{l}\text { Design } \\
\text { Quality \& } \\
\text { Context }\end{array}$ & $\begin{array}{l}\text { Aesthetics; Diversity } \\
\& \text { Attractive; Socio- } \\
\text { economic wellbeing }\end{array}$ & $\begin{array}{l}\text { Characteristic across an } \\
\text { Urban area; Positive } \\
\text { contribution }\end{array}$ \\
\hline
\end{tabular}

\section{NAGPUR, CASE StUdY}

Nagpur is centrally located and well connected to major cities in India by air, rail and road. The total area of Nagpur Municipal Corporation is 21,756 hectors with population 2405420, Census 2011 (Provisional Population Totals, Census of India 2011Provisional Population Totals, Census of India 2011; Cities having population 1 lakh and above, 2011) making gross density as 110 persons/hectors.

The city has different typology of segregated and mixed landuse. The old areas has vibrant mixed use environment that have evolved over time. The commercial or employment center (Central business district (CBD) and sub CBD) has 
dominant commercial landuse. These areas have high land and rental value making it non feasible for pure residential use so mixed landuse leads other uses. There are planned and semiplanned areas with a balance of residential and non residential activities, thus attracts the residents to be the part of these areas. There are planned segregated residential areas known as civil lines designed for automobile and not for pedestrian, but they form the greenest part of the city. The last type is the sprawl areas in the suburb planned or unplanned plotted development with residential development.

Neighborhood provides both residential \& non-residential functions through a built environment thus; six neighborhoods were selected randomly from the northern part of the city. They have variation in the landuse (figure1), spatial distribution, travel habits and socio-economic character.

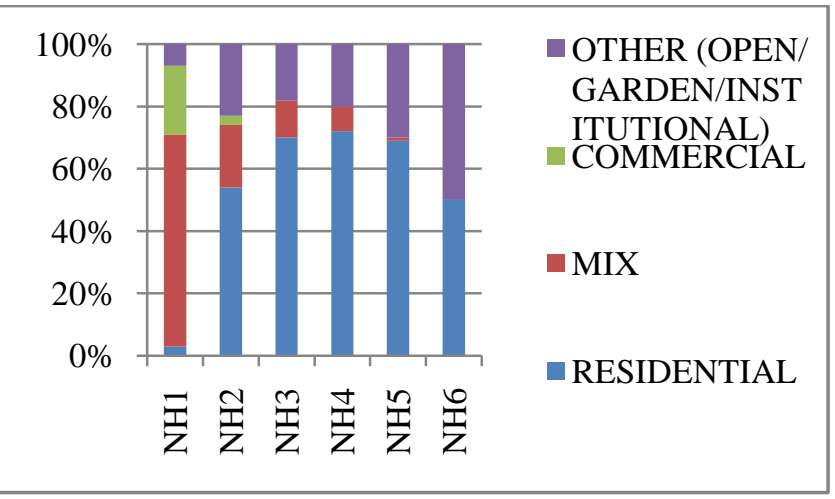

Figure1: Landuse Mix Percentage Breakup

\subsection{Neighborhoods and their Characteristics}

i. Neighborhood One (NH1) Buldi: Buldi, a 150 year old neighborhood is currently the CBD with a medium rise high density development pattern. It has a population density of 345 persons per hector with a dominant commercial landuse. Fifty years back it has adjoining occupation [caste (Group of people, each with a traditional occupation that was hereditary, closed and exclusionary)] based self sustained neighborhoods like Telipura and Gavalipura. Gradually, these have been replaced by commercial or mixed landuse. Many natives changed their occupation and migrated to new Nagpur, currently only those residents whose workplace is here, resides here.

ii. Neighborhood Two (NH2) Buddha Nagar: Buddha Nagar is a part of the sub-CBD with medium rise medium density development pattern. It has population density 255 persons per hectors with high commercial use only at the periphery major road. It's a planned plotted development dated back to fifty years dominated by a single religious group (Buddhist) with adjacent neighborhoods of Panjabi's (Sikh) and Muslim. Each of these neighborhoods has their own open spaces, religious and institutional structures.

iii. Neighborhood Three (NH3) Aahuja Nagar and Neighborhood Four (NH4) Kukreja Nagar: Aahuja Nagar and Kukreja Nagar 20-30 years planned neighborhoods are on the either side of the major sixty feet wide Nara road with low rise medium density development pattern and the density 260 and 190 persons per hectors respectively. Pure commercial is not present but it is clubbed with residential units making mixed landuse only along the major road. Within the neighborhood there is a mix of residential, institutional and open areas. NH3 residents are of lower income community involved in business and service oriented mixed ethnicity as against $\mathrm{NH} 4$ which has middle and higher income business oriented Sindhi community.

iv. Neighborhood Five (NH5) Kalpana Nagar: Kalpana Nagar is low rise low density, a decade old plannedplotted neighborhood along ring road with a current population density of 75 persons per hector. It has higher scope of increasing density. Commercial landuse is sparsely placed along the ring road in the commercial cum residential apartment.

v. Neighborhood six (NH6) Shambhu Nagar and Dhobale Layout: A sprawling development in the prior green zone with low rise low density development pattern with no ingress of any commercial or other landuse with a population density of 20 persons per hector. It lacks basic social and physical infrastructure.

\section{RESULT AND DISCUSSION}

The study is put forth in various dependent and interdependent parameters for the six neighborhoods.

Accessibility: High mix neighborhood has better access to both physical and social infrastructure as against segregated areas. NH1 being CBD acts as a transit node and is well connected to all parts of Nagpur with transit facility. $\mathrm{NH} 2$ also has good transit facility followed by $\mathrm{NH} 3$ and $\mathrm{NH} 4$, fairly in NH5 but NH6 lacks transit facility. Figure 2 shows the proximity of the basic amenities in the neighborhood. It can be noted that NH1 is highly accessible to all the facilities except for the garden as this area lacks green or open area. Even though there is proximity to gardens/open spaces in the all the neighborhoods but only the garden in $\mathrm{NH} 4$ is maintained, and residents prefer to use similar quality garden with enough facilities.

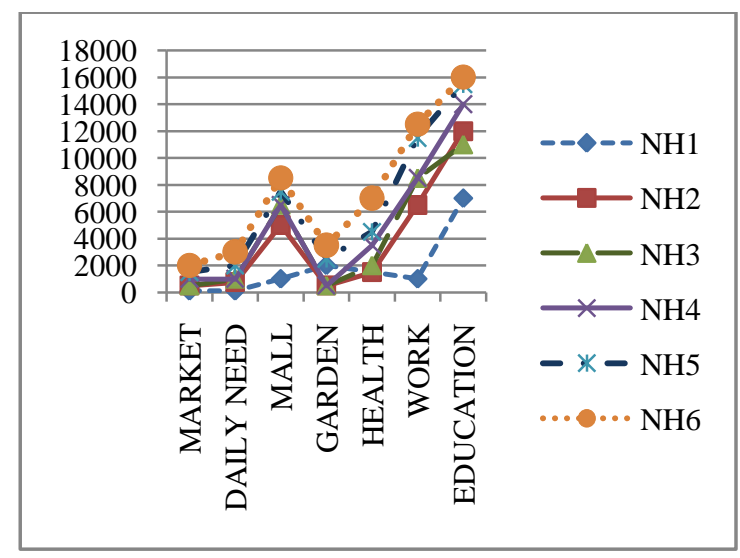

Figure 2: Distance to Various Amenities in Meters 
Trip length to work for NH1 is nearing $100 \mathrm{~m}$ as all the working population here works either in the same building or very nearby. Work trip length of $\mathrm{NH} 2,3$ and 4 is comparable due to the mix in the business and service class. Residents involved in business have their workplace in close proximity as against the service men. NH5 and 6 have high and comparable work trip length due to unavailability of job prospects nearby. Schools are within the proximity of $1.5 \mathrm{~km}$ in NH1 to 4 but the economically well off parents prefer to send their children in far away school. For higher education the overall trip length is on higher side due to the unavailability of colleges near the neighborhood.

Travel time: Increase in trip length also increases the travel time for both work and education trip in all neighborhoods except in $\mathrm{NH} 1$ for work trip (figure 3). The trip length for education of school going students is less in NH3 but time consumed is more due to the mode of travel which is either cycle or walk. Higher travel time consumption leads to less quality time available for the personal and family enrichment.

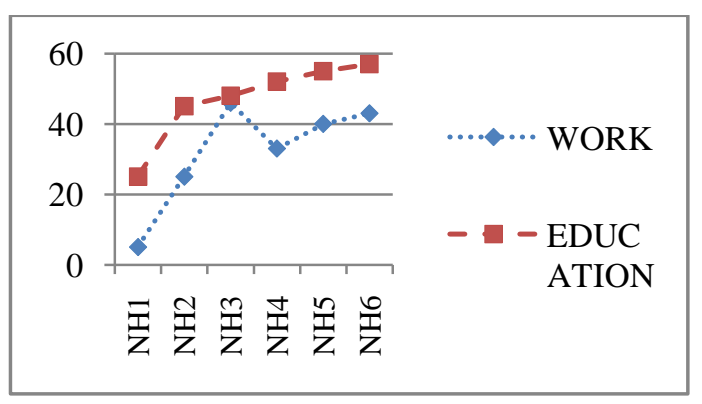

Figure 3: Travel Time in Minutes

Economic statuts and travel habits: Overall the residents in all neighbourhood except NH3 had higher range of selected middle and higher income group households. All the facilities in NH1are in close proximity thus residents spend less capital and time on travel as against NH5 and 6 where the residents need to move out for all amenities. The most vulnerable NH3 spends less money but has higher share of their income and time in travel even though they relay on walk, cycle and transit (figure 4).

The ownership of vehicles is less significant to the landuse mix but is more associated with the economic status of the individuals as against the common notion. Figure 5 shows the percentage share of different neighbourhood which is quite similar except for NH3 which is LIG dominant community.

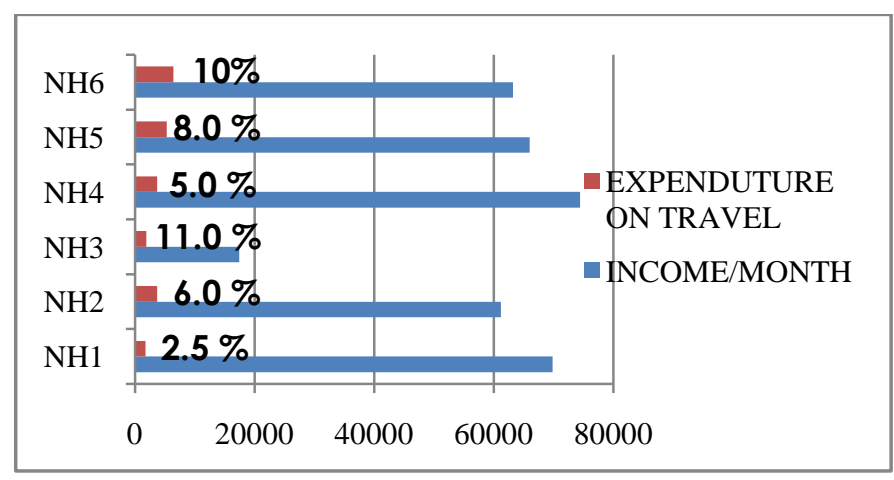

Figure 4: Travel Cost in Rupees and Percentage of Income

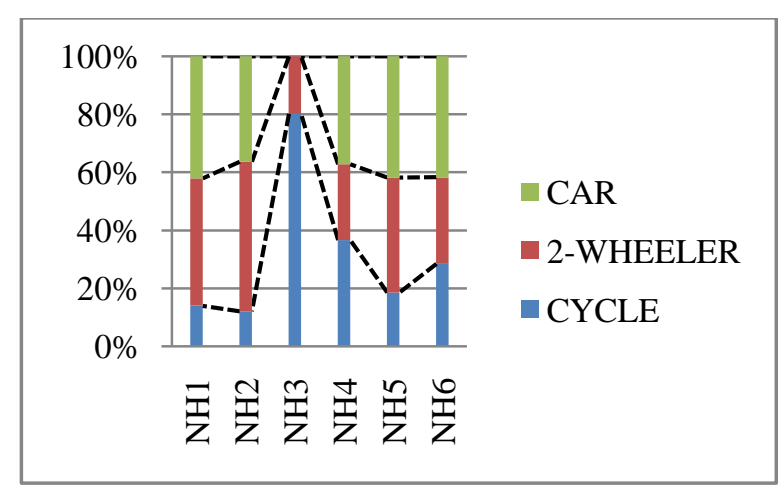

Figure 5: Vehicle Ownership in Percentage

Sense of belonging /Interaction: None of the residents feel that they have poor sense of belonging (figure 6) irrespective of the lack of the facilities in some neighbourhoods. Sense of belonging is also directly related to the age of the neighbourhood. Residents staying for the longer period tends to interact more due to the aspect of togetherness and association with the place. Streets of NH1 being commercially active are highly active through out the day but is occupied by varying strangers everyday and not the local residents. For interaction and saftey acquaintance is must. In NH2, 3 and 4 the frequency to meet, greets and talk increases due to the proximity to various facility. Also they have a community gathering on different festivals and functions. Residents in NH5 and 6 had less scope of interaction due to sparse development.

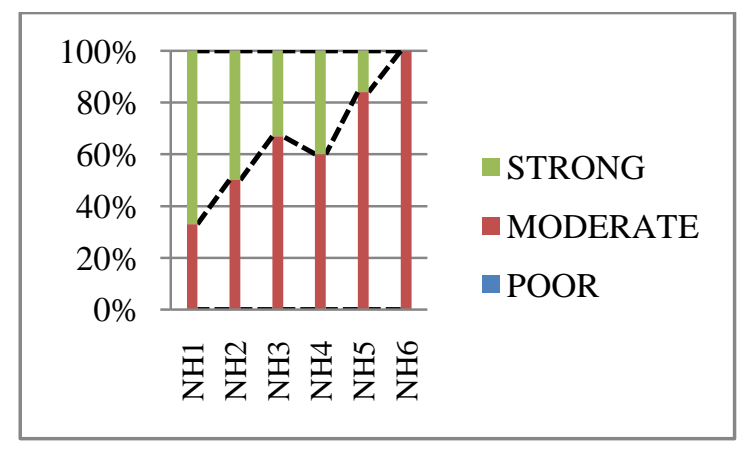

Figure 6: Sense of Belonging in percentage

Safety and Surveillance: NH1 is safe except at few commercial pockets which tend to remian vacant during night hours. Residents in NH2, 3 and 4 feel safe both on streets and home and has natural survellinace due to diverse mix. The mix of business and service oriented occupation make it vibrant and active even till late night. Except on the major periphery roads the neighborhoods are safe for all age group people. The problem of street safety is crucial in NH5 due to proximity to ring road and high heavy traffic (truck). NH6 are most vulnerable to theft even during day time due to sprawl development and lack of surveillance.

Employment: NH1 being the CBD, is the main source of employment generation, so has an intrusion of floating population. Thus, only the residents with their workplace at NH1 prefer to be a part of it and others have migrated to different parts of Nagpur. NH2, 3 and 4 has a mix of both resident's comprising their workplace nearby (business) and at 
other places (service). Residents in NH5 and 6 has to move out from their neighbourhood for work.

Infrastructure Quality: NH1 has overloaded physical and social infrastructure. There is lack of open spaces, natural light and ventilation. The major problem is noise and air pollution casued by the floating population. NH2, 3 and 4 has moderate to good social and physical infrastructure. Major problem is in NH6 which lacks the provision of basic infrstructure like municipal water supply, sewage line and street lights. There is also lack of social infrastructure like health, education and recreation facilities in NH6 making it more vulneration to unsocial activies like crime and theft.

\section{CONCLUSION}

Social sustainability being one of the three domains of sustainability plays a vital role in enhancing the community by means of giving equal opportunities, creating vibrant, diverse and inclusive environment and fulfill the social needs of the inhabitants.

Spatial planning if focuses on creating pedestrian friendly and urban environment at human scale to promote outdoor activities and which deals with improving the quality of social infrastructure like education, healthcare and interactive spaces can create social sustainability. Mixed landuse development, a spatial planning aspect tends to promote walk ability and social inclusion and create safe and accessible environment. A historic preview is put forth to describe the changing scenario of the mixed and segregated landuse in different settings. It is established that the mixed landuse promotes social sustainability as against the segregated landuse which is a contributor to social un-sustainability.

To measure the social sustainability, the mixed landuse indicators and units were developed. A correlation matrix is prepared to understand the behavior pattern thus leading to manifestation and mitigation actions.

The case study in an urban context in six neighborhoods of varying landuse mix composition supported literature study. It was observed that the highly commercial dominant neighborhood NH1 even though is highly accessible and has proximity to facilities but has problem of open space requirement (lack of natural light and ventilation and playing/ interacting space for different age group people), noise and air pollution caused by floating population and overloading of infrastructure due to high commercial activities. NH5 and 6 with sparse development had the problems associated with lack of basic social and physical infrastructure facilities thus created social exclusion, inequality and lack of interaction amongst the residents. Even though these areas had lot of open spaces due to vacant plot but there is lack of quality garden or community space which can act as a platform for the interface. But NH2, 3 and 4 which had a balance of the amenities and infrastructure facility, mix of land uses and mix of housing typologies are preferred option of the residents. Also residents belong to a similar cultural group shares common interest involving them in the community/social gathering.

At the end it can be concluded that very high mix of one landuse (like commercial) or no mix (segregated) landuse lacks the social and physical infrastructure thus are not socially sustainable. Residential neighborhood with commercial mix on the periphery road and other institutional mix tends to be more active and has better quality of life thus are socially sustainable.

This study is a part of the ongoing research work. It can further be extented to establish the optimum mix to achive social sustainability in an urban area. This can help the policy maker to formulate the norms and conserve the social aspect.

\section{BIBLIOGRAPHY}

[1] Brundtland Commission, "Report of the World Commission on Environment and Development," 1987.

[2] Richmond. http://www.richmond.ca/services/Sustainable/social/about.htm.

[3] T. Hancock. http://newcity.ca/Pages/social_sustainability.html.

[4] J. Gehl, Life Between buildings, Using Public Space. New York: Arkitektens Forlag, the Danish Architectural Press, 1971.

[5] L. Kavanagh, "Social Sustainability \& High Density Development," in PIA Queensland, 2010

[6] A. Petersen, "Social Sustainability Policy," 2009.

[7] R.S. Kotharkar and S.P. Bahadure, "Mixed Landuse, An approach to Sustainable Urban Development," in International Conference Urbanism and Green Architecture titled Mixed Landuse, An approach to Sustainable Urban Development, NIT, Hamirpur, Pp. 149-158, 2010.

[8] L. Eric and B. Frank, "From mixed to multiple landuse," Journal of Housing and the Built Environment, Pp. 1-13, 2006.

[9] D. Procos, Mixed Land Use: From Revival to Innovation. Stroudsburg, Pennsylvania: Dowden, Hutchingon \& Ross, Inc., 1976.

[10] G. Rosalind, S. Francisco and S. Martim, "Urban Spatial Segregation: Forces, Consequences, and Policy Responses," Land Lines, Vol. 12, No. 6, 2000.

[11] A. Legeby, "Accessibility and Urban Life Aspects on Social Segregation," in 7th International Space Syntax Symposium, Stockholm, Pp. 064:1-11, 2009.

[12] J. Jacobs, "The Death and Life of Great American Cities." 1961.

[13] A. Coupland, "Reclaiming the City: Mixed Use Development,"S.A. Aytur et al, "Health Promoting Community Design, Promoting Active Community Environments Through Land Use and Transportation Planning," The science of Health Promotion, Vol. 21, No. 4, Pp. 397407, March/April 2007.

[14] B. Barbara et al, "Mixed land use and walk ability: variations in land use measures and relationships with BMI, Overweight, and Obesity," Health Place, Pp.1130-41, 2009.

[15] L.S. Anastasia and F. Camille, "Addressing women's fear of victimization in transportation settings: A survey of U.S. transit agencies," Urban Affairs Review, Vol. 44, No. 4, Pp. 554-587, 2009.

[16] DCLG, "Mixed use development, practice and potential," Department for Communities and Local Government, May 2006.

[17] S. Handy, "Urban form and pedestrian choices: A study of four Austin neighborhoods," Transportation Research Record, Vol. a, 1552, Pp. 135144, 1996.

[18] Texas Community Design Committee, "Mixed Use Matters, Our Cities, Our Region, Our Future; Beginning a Regional Conversation about, How We Can Better Design Mixed-Use Communities," Texas, 2008.

[19] E.A. Tombari, "Smart Growth, Smart Choices Series: Mixed-Use Development," AICP Land Development Series, National association of home builders (NABH), January 2005.

[20] ODPM, "Tackling Anti-social Behavior in Mixed Tenure Areas," Office of the Deputy Prime Minister, London, 2003.

[21] K. Saville-Smith, "The Value of Neighborhood Intensification: The Interface Between Dwelling, Neighborhood Design and Affordability, New Zealand," in URBAN DYNAMICS \& HOUSING CHANGE Crossing into the 2nd Decade of the 3rd Millennium 22nd International Housing Research Conference, Istanbul, 2010.

[22] S.P. Bahadure and R.S. Kotharkar, "Social Sustainabality and Mixed Landuse," in International Conference on Advances in Architecture and Civil Engineering (AARCE) 2012, Coimbatore, India, 2010, Pp. 725731.

[23] (2011) Government of India, Ministry of Home Affairs. [Online]. http://censusindia.gov.in/2011-prov- 
results/paper2/data_files/India2/Table_3_PR_UA_Citiees_1Lakh.pdf

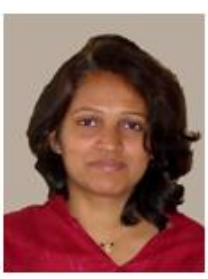

Sarika Bahadure, Female, DOB $19^{\text {th }}$ August 1976, Bhandara, Maharashtra, India. Education Qualifications: i) PhD, Visvesvaraya National Institute of Technology (VNIT), Nagpur, India; Registered in July 2010; ii)Masters in Urban Planning, VNIT, Nagpur, India (2007-09); iii)Bachelor of Architecture, Visvesvaraya Regional College of Engineering, Nagpur, India (1994-99).

Work Experience: Assistant Professor, Department of Architecture, VNIT, Nagpur, India (since July 2008 till date); and Lecturer, Department of Architecture, KITS, Ramtek, Nagpur, India, (September 2000 to July 2007). Memberships in Professional Societies: Associate Member of Council of Architecture, Regd. No. CA/99/25519 and Institute of Town Planner, New Delhi, India: Regd. No. ITPI/2012/028.

Publications at International Conferences: [1] R.S. Kotharkar and S.P. Bahadure, "Mixed Landuse, An approach to Sustainable Urban Development," in International Conference Urbanism and Green Architecture titled Mixed Landuse, An approach to Sustainable Urban Development, NIT, Hamirpur, pp. 149-158, 2010. [2] P.N. Bahadure and S.P. Bahadure, "Sustainable Urban Development in India: Challenges and Approaches," in International Conference on Advances in Architecture and Civil Engineering, Coimbatore, India, pp. 712-719, 2012.

Ongoing PhD Research "Mixed Landuse, A Tool for Sustainable Urban Development", it studies the feasibility of the concept of mixed land use for sustainable urban development in the urban context of Nagpur city, India.

Email: sarika_wa@yahoo.com 